\title{
Communication
}

\section{Initial Effects of the SB Natural Anticancer Drug on the Number of NK Cells, CD4+ and CD8+ T Lymphocytes in Human Peripheral Blood}

\author{
Jong-Hwa Lee ${ }^{1,2}$, Yoo-Jin Cho ${ }^{1,2}$, Myung-Sup Chae ${ }^{3}$, Wang-Jae Lee ${ }^{4}$, U-Hyun Park ${ }^{5,6}$, \\ Euishin Edmund Kim ${ }^{5,7,8}$, \\ ${ }^{1}$ Department of Internal Medicine, Sahmyook Cancer Center, Sahmyook Seoul Hospital, Seoul, Korea \\ ${ }^{2}$ Department of Internal Medicine, Sahmyook Seoul Hospital, Seoul, Korea \\ ${ }^{3}$ Department of Family Medicine, Sahmyook Seoul Hospital, Seoul, Korea \\ ${ }^{4}$ Department of Anatomy, College of Medicine, Seoul National University, Seoul, Korea \\ ${ }^{5}$ Department of Medical Oncology, Kyunghee University Hospital, Seoul, Korea \\ ${ }^{6}$ Department of Internal Medicine, East-West Integrative Medicine Hospital, Wien, Austria \\ ${ }^{7}$ Department of Molecular Medicine, Graduate School of Convergence Science and Technology, Seoul National University, Seoul, Korea \\ ${ }^{8}$ Department of Radiological Sciences, University of California Medical Center, Irvine, USA
}

Email address:

eedkim@yahoo.com (E. E. Kim)

${ }^{*}$ Corresponding author

\section{To cite this article:}

Jong-Hwa Lee, Yoo-Jin Cho, Myung-Sup Chae, Wang-Jae Lee, U-Hyun Park, Euishin Edmund Kim. Initial Effects of the SB Natural Anticancer Drug on the Number of NK Cells, CD4+ and CD8+ T Lymphocytes in Human Peripheral Blood. Journal of Cancer Treatment and Research. Vol. 6, No. 2, 2018, pp. 25-30. doi: 10.11648/j.jctr.20180602.13

Received: May 24, 2018; Accepted: July 19, 2018; Published: August 14, 2018

\begin{abstract}
Most anticancer drugs produce cytotoxicites in cancer cells, but also generate effects in normal cells that create undesirable side effects, especially for immune functioning cells which have already been suppressed by cancer invasion or biological effects. The SB natural anticancer drug is a root extract of the Pulsatilla koreana plant that has been used in Korea as an effective anticancer agent for more than 20 different malignant tumors without triggering significant adverse reactions. We investigated the effects of the SB anticancer drug on human immune cells in cancer patients. 24 consecutive patients, with histologically proven cancers, received SB drug treatments and 20 control patients did not receive SB administrations. Both groups were immunologically tested before and after their SB treatments for 14 days and then weekly for the $3^{\text {rd }}, 4^{\text {th }}, 5^{\text {th }}$ and $6^{\text {th }}$ weeks thereafter. The total number of white blood cells with differential counts including monocytes and lymphocytes were checked. Immunoassay and flow cytometry were used to analyse CD4 and CD8 T cell percentages, total cell counts with their ratios, as well as CD16/56 natural killer cell percentages and cell counts. Total white blood cell counts normalized within 10 days after the SB drug administrations. The total lymphocyte counts were slightly increased, but remained within normal parameters. CD4 and CD8 T cells, as well as CD 16/56 NK cell percentages, became normal within 10 days; their total cell counts were initially increased $(26.3 \%, 45.2 \%$, and $16.7 \%$, respectively) and then became normal. The SB drug was found to be effective cytoapoptotically and was also effective for immune cell recovery in cancer patients in their initial period of the SB drug treatment. These were patients who had already had a bone marrow suppression by cancer invasion and/or prior chemotherapy.
\end{abstract}

Keywords: Initial Effects, The SB Natural Anticancer Drug, NK Cells, CD4+ and CD8+ T Lymphocytes, Human Peripheral Blood 


\section{Introduction}

In advanced cancer treatments, anticancer drugs have commonly been used for more than half of century until now. Most of anticancer drugs impact their cytotoxicities, not only on cancer cells, but also on normal cells. This causes undesirable toxic side effects, especially on immune functioning cells. The patient's immunity is generally impaired by the bone marrow suppression caused by cancer cell invasion, resulting in severe infections and rapid cancer dissemination $[1,2]$.

A T cell is a type of lymphocyte that plays a central role in cell-mediated immunity. $\mathrm{T}$ cells mature in the thymus from thymocytes. Eventually they have one of two distinct phenotypes on their surface-CD4 or CD8. CD4 T cells are generally called "Helper $\mathrm{T}$ cells" (Th) that send helpful signals to produce antibody production in other types of lymphocytes, like B lymphocytes, which play a key role in antibody production. There are many subsets in CD4 T cells, such as Th1, Th2, Th17 cells, follicular helper T (Tfh) cells and even regulatory $\mathrm{T}$ (Treg) cells. Their functions are so diverse that they are stimulatory in some cases, while being inhibitory in others. CD8 T cells are also called cytotoxic T cells. These have killer functions for virus-infected or tumor cells.

The CD4/CD8 ratio measures the ratio of $\mathrm{T}$ helper cells to cytotoxic cells. The ratio in healthy adults is $2: 3$. Although it must be said that the ratio itself has limited value because of the functional diversity of CD4 T cells among several distinct subsets. The ratio does, however, roughly reflect the immune status of each individual. The altered ratio can actually indicate diseases relating to immune deficiency or autoimmunity. For example, an inverted ratio, namely less than two, might indicate an impaired immune system. A reduced ratio is associated with a decreased resistance to infection. A high ratio is associated with patient survival as in non-small cell lung cancer [3].

The SB natural anticancer drug is a root extract of Pulsatilla koreana and has been used in Korea more than 20 years as an effective anticancer agent for various kinds of malignancies without significant toxicities in many preclinical and clinical trials [4-7]. Its apoptotic Pulsatilla saponin D fraction [8], and antiangiogenic, as well as immune potentiative deoxypodophyllotoxin components [9] have been well reported.

We investigated the effects of the SB anticancer drug on human immune functioning cells after treating them by intravenous and percutaneous direct intratumoral injections in advanced cancer patients.

\section{Methods and Materials}

Patient selection took place between April 2014 and September 2014. 24 consecutive advanced and recurrent cancer patients, who had been diagnosed histologically, were admitted to Sahmyook Seoul Hospital for SB anticancer drug treatment. There were also 20 control patients in the same hospital during the same time period who did not receive SB anticancer treatments. The performance status was $3-4$, an absolute granulocyte $>1,500 / \mathrm{uL}$, hemoglobin level $>10 \mathrm{~g} / \mathrm{dL}$, platelet count $>50,000 / \mathrm{uL}$ and adequate renal and hepatic function, creatinine and bilirubin $<1.5 \mathrm{x}$ upper limit of normal (ULN), AST and ALT <2.0x ULN. Exclusion criteria included concurrent other malignancies and serious medical conditions that would impair the ability of the patient to receive protocol treatment. Venous bloods were collected from each patient for immunological tests on scheduled days before and after the SB drug administrations during the first 14 days and then weekly for the $3^{\text {rd }}, 4^{\text {th }}, 5^{\text {th }}$ and $6^{\text {th }}$ weeks thereafter.

Informed consent was obtained from all individual participants in our study. All procedures performed in our study were in accordance with the ethical standards of the institutional research committee and with 1964 Helsinki declaration.

Assessment of data Total white blood cell counts with differential counts including monocytes and lymphocyte were analyzed. CD4, CD8 T cells and CD16/56 natural killer cell percentages, as well as total cell counts, were obtained by immunoassay using the flurochrome conjugated monoclonal antibody for CD4, CD8 and CD16/56 antigen counting and using flow cytometry.

Statistical Analysis All statistical analyses were performed with SPSS software (version Chicago, IL USA) and a p-value less than 0.05 were considered statistically significant.

\section{Results}

Total white blood cell counts (normal range: 4,100$10,200 / \mu \mathrm{L}) \quad 8,798.5 \pm 7,931.4 / \mu \mathrm{L}$, increased in 5 patients $(20.8 \%)$ and decreased in one patient $(4.2 \%)$ before the SB administrations. After the SB administrations they had $8,471.0 \pm 3,508.8 / \mu \mathrm{L}$, increased in 3 patients $(12.5 \%)$ and decreased in one patient $(4.2 \%)$. They were normal within 10 days (Figure 1). Monocyte counts (normal range: 0-1,200) were $763.1 / \mu \mathrm{L}$ on average and increased in 2 patients before SB administrations. They were decreased to $562.5 / \mu \mathrm{L}$ after SB administrations. In the control group they decreased from $991.4 / \mu \mathrm{L}$ to $459.9 / \mu \mathrm{L}$.

Total lymphocyte counts (normal range: 460-5,100/ $\mu \mathrm{L}$ ) were $1,334.0 / \mu \mathrm{L}$ on average, and increased to $2,997.7 / \mu \mathrm{L}$ after the SB administrations, but remained within normal ranges (Figure 1). CD4 T cell percentages (normal range: 29$57 \%$ ) were $40.3 \%$ on average before SB administrations. They increased in one patient $(4.2 \%)$ and decreased in 4 patients $(16.6 \%)$ with $577.6 \pm 434.3 / \mu \mathrm{L}$ of total cell counts on average (normal range: $750-820 / \mu \mathrm{L}$ ). In the control group the cell counts also decreased to $522.8 \pm 189.5 / \mu \mathrm{L}$. After SB administrations, the CD4 $\mathrm{T}$ cell percentage was $38.6 \%$ on average. It increased in two patients $(8.3 \%)$ but decreased in 5 patients $(20.8 \%)$, whose counts were increased to 
$729.7 \pm 309.6 / \mu \mathrm{L}$ of total cell counts within 10 days. In the control group they decreased to $212.0 \pm 220.6 / \mu \mathrm{L}$ (Figure 2). Before SB administration, the CD8 T cell percentage (normal range: $11-38 \%$ ) was $27.2 \%$ on average. This increased in two patients $(8.3 \%)$, decreased in two patients $(8.3 \%)$, and total cell counts (normal range: $450-500 / \mu \mathrm{L}$ ) were found to be $396.4 \pm 348.9 / \mu \mathrm{L}$ in $\mathrm{SB}$ patients and $403.3 \pm 321.3 / \mu \mathrm{L}$ in control group. After the SB administrations, the CD8 T cell percentage was $34.9 \%$ on average. It increased in 8 patients $(33.3 \%)$ who were normal within 10 days with 574.9 $\pm 430.3 / \mu \mathrm{L}$ of total cell counts. This was a significant increase of $(45.2 \%, \mathrm{p}<0.05)$ that is $20.1 \%$ above normal. However, in the control group the CD8 $\mathrm{T}$ cell counts were markedly decreased to $113.4 \pm 148.4 / \mu \mathrm{L}$ (Figure 3 ). The $\mathrm{CD} 4 / \mathrm{CD} 8$ ratio (normal range: 1.71-1.92) was 1.60 on average in the SB treatment patients and 1.47 in the control group before SB administration. After SB administration the average ratio was 1.33 in SB patients and increased markedly to 4.54 in the control group.

The CD 16/56 natural killer (NK) cell percentage (normal range: $5-35 \%$ ) was $15.3 \%$ on average in SB patients, and increased in two patients $(8.3 \%)$ while it decreased in one patient $(4.2 \%)$ before SB administration. Total cell counts (normal range: $280-320 / \mu \mathrm{L}$ ) were $270.8 \pm 196.7 / \mu \mathrm{L}$ in patients who received SB treatment and $397.8 \pm 288.0 / \mu \mathrm{L}$ in the control group. After SB administration, the CD 16/56 NK cell percentage was on average $(21.4 \%)$, and decreased in two patients $(8.3 \%)$, but normalized 3 days later, with a total cell count $(316.1 \pm 169.1 / \mu \mathrm{L}) \quad(16.7 \%$ increments $)$. The immune system was boosted by an increment of $16.7 \%$. In the control group it was, however markedly decreased to a cell count of $186.2 \pm 257.1 / \mu \mathrm{L}$ (Figure 4 ).

Table 1. Characteristics of enrolled patients.

\begin{tabular}{lll}
\hline Variables & SB Treated Group & Control Group \\
\hline No. of cases & 24 & 20 \\
Age range (yrs.) & $27-80$ & $35-79$ \\
(median) & $(56.5)$ & $(59.5)$ \\
Male & 8 & 8 \\
Female & 16 & 12 \\
Lung ca. & 1 & 5 \\
Pancreas ca. & 12 & 10 \\
Liver ca. & 1 & 1 \\
Biliary ca. & 1 & 0 \\
Stomach ca. & 2 & 4 \\
Colon ca. & 3 & 0 \\
Ovary ca. & 2 & 0 \\
Lymphoma & 1 & 0 \\
Performance scale & $3-4$ & $3-4$ \\
\hline
\end{tabular}

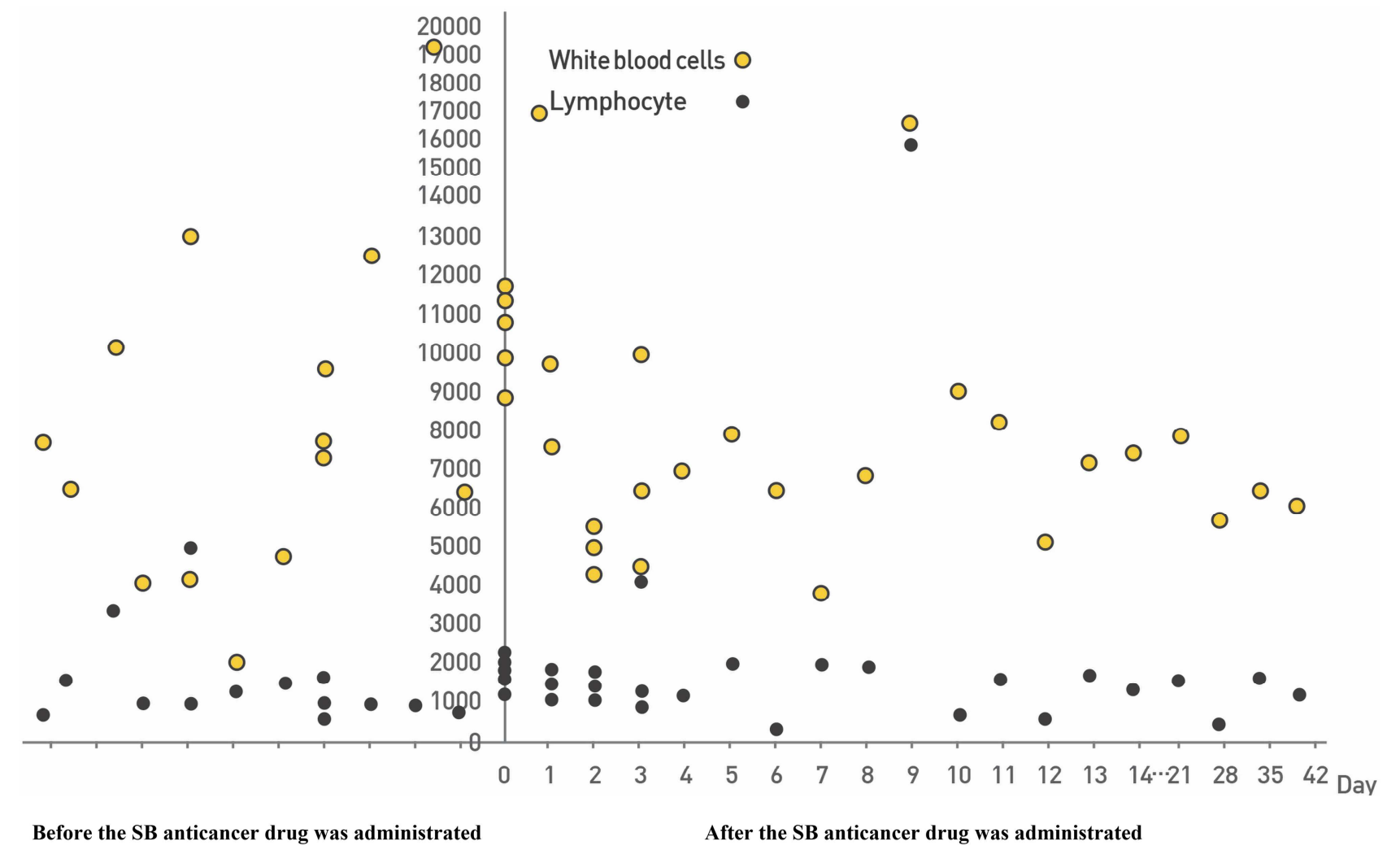

Figure 1. The changes of white blood cell counts and lymphocyte counts before and after SB drug administration.

The number of total white blood cells and monocytes in 24 consecutive advanced and recurrent cancer patients were recorded before and after SB administrations, as described in Materials and Methods. Patients were monitored for 10 days before the administrations and for 42 days after the administrations. 


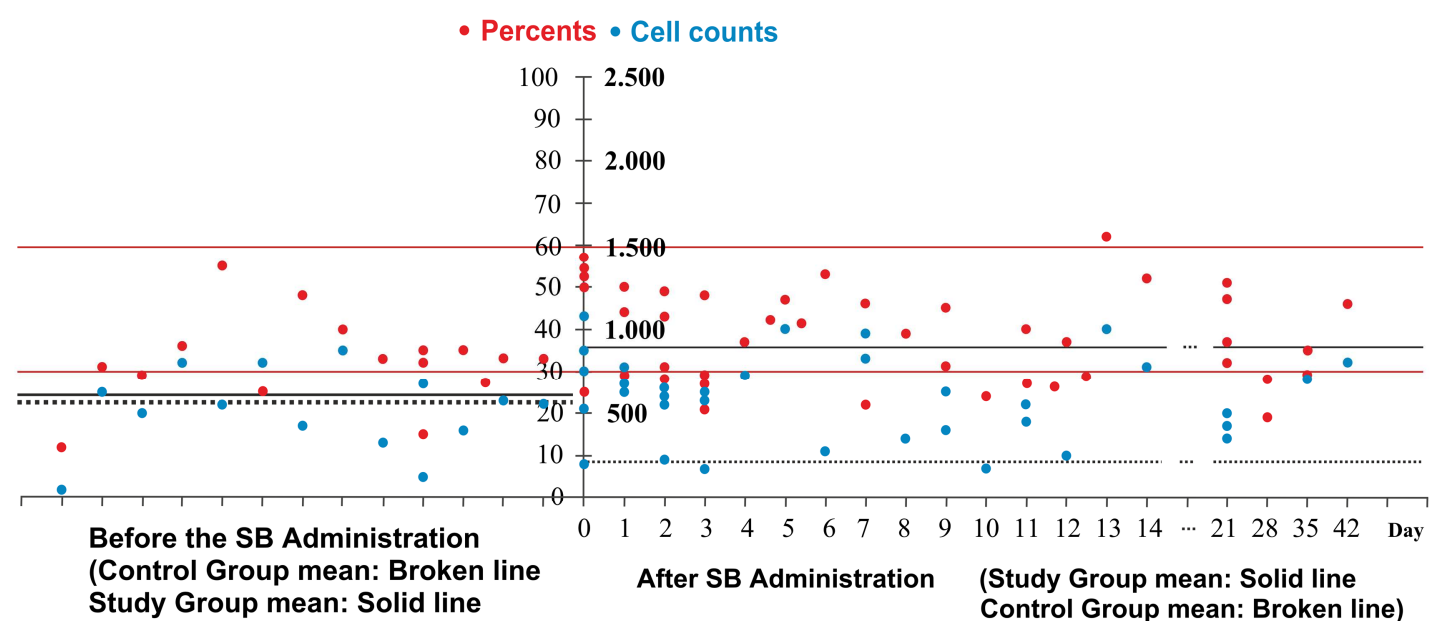

Figure 2. $\mathrm{CD}^{+}$T cell changes after SB anticancer drug administration.

The number of $\mathrm{CD}^{+} \mathrm{T}$ cells in 24 consecutive advanced and recurred cancer patients were recorded before and after SB administrations as described in Materials and Methods. Patients were monitored for 10 days before administrations and for 42 days after administrations. The SB drug boosted the patient's immune systems.

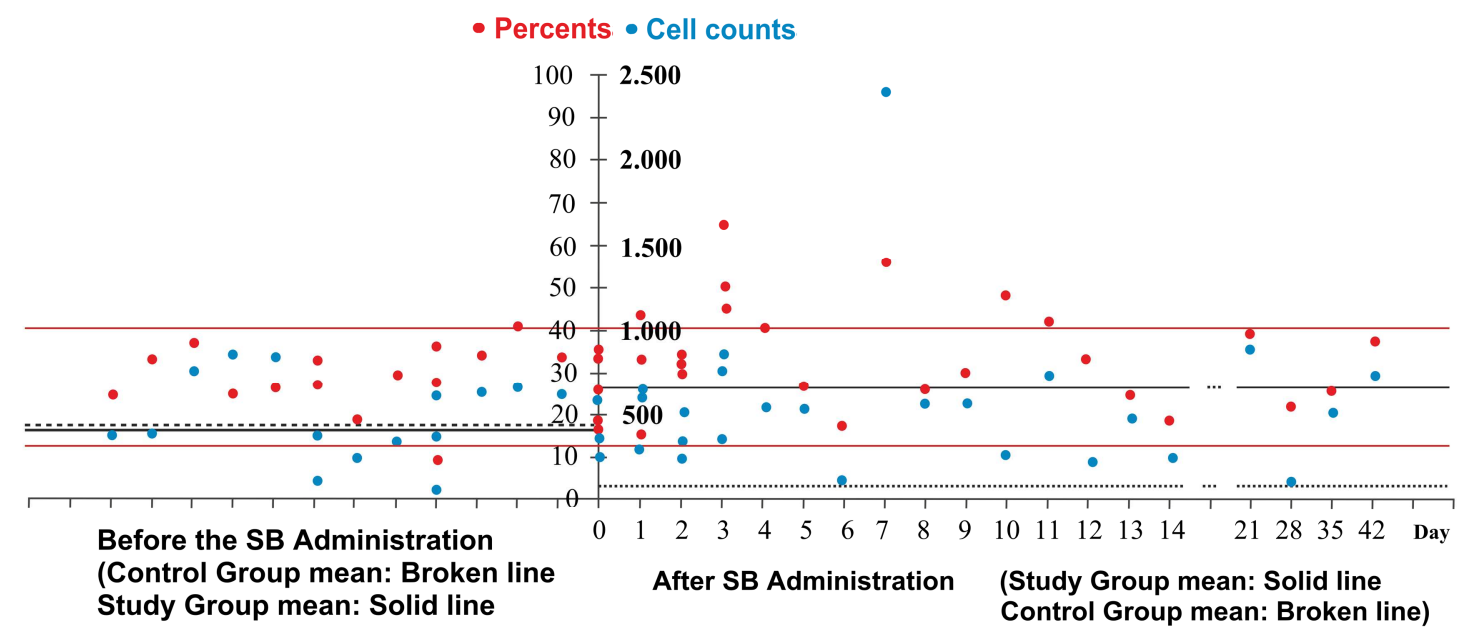

Figure 3. $C D 8^{+} T$ cell changes after $S B$ anticancer drug administration.

The number of $\mathrm{CD}^{+} \mathrm{T}$ cell in 24 consecutive advanced and recurrent cancer patients were measured before and after SB administrations as described in Materials and Methods. Patients were monitored for 10 days before administrations and for 42 days after administrations. The SB drug boosted the patient's immune systems.

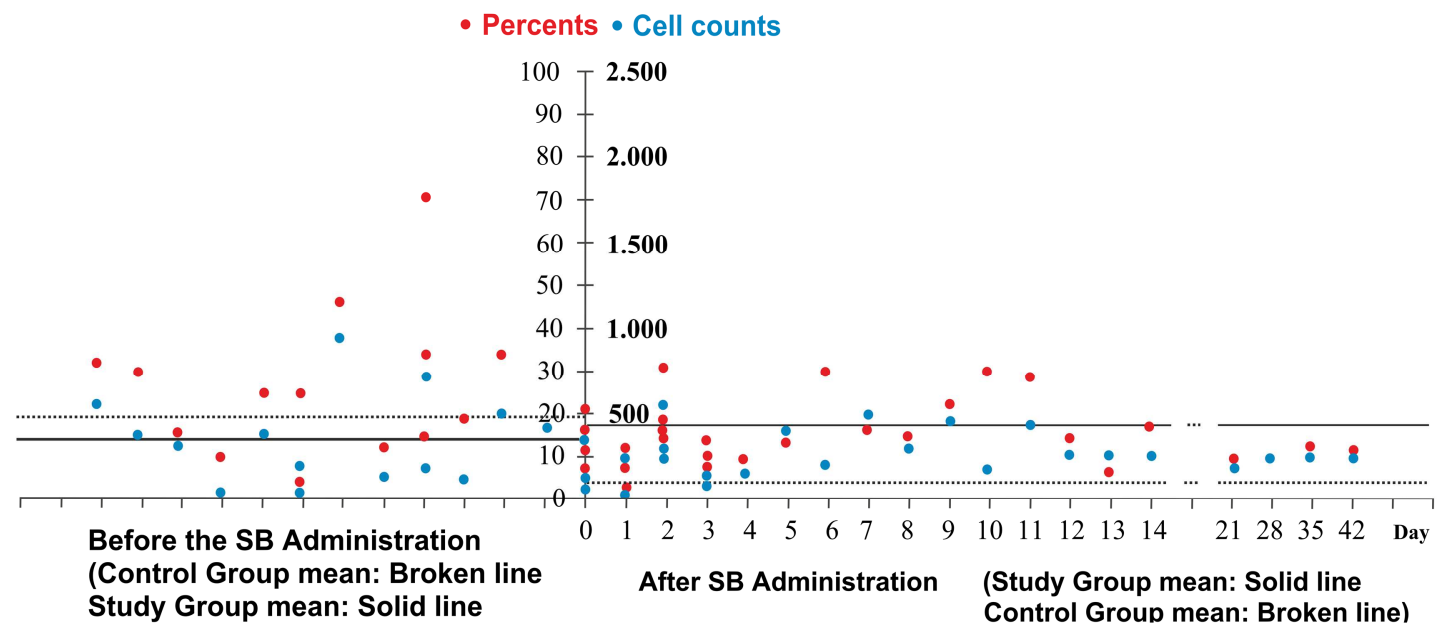

Figure 4. NK cell changes after SB anticancer drug administration. 
The number of $\mathrm{CD}^{+} \mathrm{T}$ cells in 24 consecutive advanced and recurrent cancer patients, were measured before and after SB administrations, as described in Materials and Methods. Patients were monitored for 10 days before administrations and for 42 days after administrations. The SB drug boosted the patient's immune systems.

\section{Discussion}

Cancer cells weaken the immune system by spreading into the bone marrow and thus diminish its hematopoietic function. Surgical stress also can suppress the immune system and therefore the granulocyte function as well as numbers of lymphocytes are decreased after major surgery $[10,11]$. Most anticancer drugs and radiation therapy produce cytotoxicities, not only in the cancer cells, but also in normal cells. That produces undesirable side effects, especially in immune functioning cells, which are severely depleted by bone marrow suppression. This results in severe infection as well as rapid cancer metastases.

Our data reveals that total white blood cell counts were not significantly changed, but monocyte counts were slightly decreased after SB administration. However, one of the other well-known natural anticancer drug studies using mistletoe reported that total white blood cell and monocyte counts were increased, probably due to its immunogenic lectin component [12]. Disrupted CD4 $\mathrm{T}$ cell percentages were normalized 10 days after the $\mathrm{SB}$ administration, and decreased cell counts were moderately increased to the normal level seen within the healthy Korean population [13]. Disrupted CD8 T cell percentages were also normalized after 10 days of SB administration, and the cell counts were increased significantly. These remained at the level of the healthy Korean population thereafter [13]. CD4/CD8 ratios were slightly decreased after SB administrations, because the number of CD8 $\mathrm{T}$ cells were increased, but increased severely in the control group as was seen in a study by Hong et al. who reported an increased ratio with most gastric cancer patients [14].

The SB drug contains a deoxypodophyllotoxin, which has an antiangiogenetic effect on cancer cells and also promotes the activation of CD8 T cells by dendritic cells [9]. CD16/56 NK cell percentages were within a normal range shortly after the SB administration, and cell counts were not significantly changed. Takenchi et al. [15] reported that gastric cancer patients with less than $25 \% \mathrm{NK}$ cell activity showed a high incidence of recurrence with lymphatic involvement. We also confirmed a low recurrence of gastric cancer patients with more than $25 \%$ of NK cell activity, although our sample size of patients was relatively small. CD 16/56 cell counts were reported to be increased by mistletoe treatment [16], but Kim et al. [12] could not find a significant effect of mistletoe treatment on CD16/56 cells in Korean gastric cancer patients. Our study also revealed no significant increment of NK cell counts after the SB drug administration. NK cell counts normalized at the level of the healthy Korean population within a relatively short time.

We believe that the SB drug is a good and effective cytoapoptotic anticancer drug that rejuvenates the immune system so that it can be combined with other kinds of immune activating vaccines [17]. One aspect of chemotherapeutic resistance is the inability of the chemotherapy to eliminate cancer stem cells (CSC). A another option is to use monoclonal antibodies to target these CSC's. This has already been the subject of several studies [18-20]. This new research shows that there is a potential to combine conventional chemotherapy with SB administration for a synergistic and effective treatment that does not produce adverse reactions.

The SB anticancer drug normalized total white blood cell counts within 10 days, thus achieving normal total lymphocyte counts. CD4 and CD8 T cell percentages were also normalized within 10 days after SB administration. CD4 $\mathrm{T}$ cell counts were slightly increased, while CD8 $\mathrm{T}$ cell counts were substantially increased, so that patients' immune systems returned to normal levels. CD16/56 NK cell percentages were normalized shortly after the administration of the SB drug with a moderate increase in the total cell count, giving patients an average status.

\section{Conclusion}

Our investigation on the initial effects of the SB anticancer drug on immune cells of cancer patients demonstrates normalized total white blood cells within 10 days after SB administration. Total lymphocyte counts were slightly increased initially. CD4 and CD8 T cells as well as CD 16/56 NK cell percentages also became normal within 10 days and their total cell counts were initially increased. Therefore, the $\mathrm{SB}$ is effective cytoapoptotically for immune recovery in cancer patients during the early period of their treatments.

\section{Compliance with Ethics}

None of authors has conflict of interest related to our study.

\section{References}

[1] Hersh EM (1974): In Antineoplastic and Immunosuppressive agents. Part 1. Sartorelli AC and Johns DG (eds). New York. Springer-Verlag Inc p577.

[2] Marsh JC (1976): The effects of cancer chemotherapeutic agents on normal hematopoietic precursor cells. A review. Cancer Res 36:1853.

[3] Jackute J, Zemaitus M, Pranys Dand Sakalauskas R (2015) The prognostic influence of tumor infiltrating CD4 and CD8 cells in resected NSCLC. J Inflamm: 63-69.

[4] Kang SS (1989) Saponins from the roots of Pusatilla koreana. Arch Pharm Res 12:42-47.

[5] Kim SY and Kim SB (1994) Antitumor effect of extract of Pulsatilla koreana in vitro. J Korean Cancer Asso 26 (6):959963. 
[6] Hwang JS and Kim SH (2001) Proliferation assay of SB injection on $\mathrm{T}$ and $\mathrm{B}$ lymphocyte in $\mathrm{SD}$ rat splenocytes. Biotoxtech 667-699.

[7] Moon KS, Ji JY, Cho YJ, Lee JH, Choi MS and Kim EE (2015) Therapeutic effects of SB natural anticancer drug in 50 patients with stage IV pancreatic cancer. J Cancer Tre and Res $3(3): 42-46$.

[8] Kim Y, Bang SC, Lee JH and Ahn BZ (2004) Pulsatilla saponin D; The antitumor principle from Pulsatilla koreana. Arch Pharm Res 27: 915-918.

[9] Kim Y, Kim SB, You YJ and Ahn BZ (2002) Deoxypodophyllotoxin; The cytotoxic and antiangiogenic component from Pusatilla koreana. Planta Medica 68:271-274.

[10] Ogawa K, Hirai M, Katsube T, Muroyama M, Hamaguchi K, Shimakawa T et al. (2000) Suppression of cellular immunity by surgical stress. Surgery 127:329-336.

[11] Woo JH, Baik HJ, Kim CH, Chung RK, Kim DY, Lee GY et al. (2015) Effects of propofol and desflurane on immune cell populations in breast cancer patient.. A Randomized Trial. J Korean Med Sci 30 (10):1503-1508.

[12] Kim KC, Yook JH, Eisenbraun J, Kim BS and Huber R (2012) Quality of life, immunomodulation and safety of adjuvant mistletoe treatment in patients with gastric carcinoma. a randomized, controlled pilot study. BMC Complement Altern Med 12:172.

[13] Choi JB, Lee SJ, Lee YA, Maeng HG, Lee Jk and Kang YW (2014) Reference values for peripheral blood lymphocytes subsets in a healthy Korean population. Immune Netw 14 (6):289-295.
[14] Hang WS, Min YI, Son YS and Hong SI (1995) Peripheral blood lymphocyte subset in patients with stomach cancer. J Korean Med Sci 10 (3):164-168.

[15] Takeuchi H, Machara Y, Tokunaga E, Koga T, Kakeji Y and Sugimach K (2001) Prognostic significance of natural killer cell activity in patients with gastric carcinoma. a multivariate analysis. Am J Gastroenterol 96 (2):574-578.

[16] Buessing A, Stumpf C, Troeger W and Schietzel M (2007) Course of mitogen stimulated $\mathrm{T}$ lymphocytes in cancer patients treated with Viscum album extracts. Anticancer Res27:2903-2910.

[17] Chung MJ, Park JY, Bang SM, Park SW and Song SY (2014) Phase II clinical trial of ex vivo-expanded cytokine induced killer cell therapy in advanced pancreatic cancer. Cancer Immunol Immunother 63:939-946.

[18] Edris B, Weiskopf K, Volkmer AK, Volkmer JP, Willingham SB, Contreras Trujillo $\mathrm{H}$ et al (2012) Antibody therapy targeting the CD47 protein is effective in a model of aggressive metastatic leiomyosarcoma. Proc Natl Acad Sci USA 109:6656-6661.

[19] Yoshida K, Tsujimoto H, Matsumura K, Kinoshita M, Takahata R, Matsumoto $\mathrm{Y}$ et al (2015) CD47 is an adverse prognostic factor and therapeutic target in gastric cancer. Cancer Med 4:1322-1333.

[20] Sneha S, Nagare RP, Priya SK, Sidhanth C, Pors K (2017) Therapeutic antibodies against cancer stem cells:a promising approach. Cancer Immunol Immunother 66:1-16 (review). 